\title{
Bioethics and Food Restrictions by Religious Motivations: Decision Making Processes in Health
}

\author{
Marília Fernandes Wettstein ${ }^{1}$, Lia Nunes Ferreira Alves ${ }^{1}$ and José Roberto Goldim²,1*
}

${ }^{1} P P G$ in Medicine: Medical Sciences, Federal University of Rio Grande do Sul, Brazil

${ }^{2}$ Bioethics Division, Hospital de Clinicas de Porto Alegre, Brazil

\begin{abstract}
Bioethics reflects on many issues in health, one is the spiritual aspects involved in decision making. The inclusion of these aspects does not remove the secular character of bioethical reflection, in contrast, allows you to have a broad and complex motivations associated with the decisions that people make. We conducted a cross-sectional study with a sample of 271 inpatients at a university general hospital in Porto Alegre, Brazil. Individual interviews were conducted focusing on the issue of food shortages and the motivations involved, as well as expression of coercion associated. With respect to food, $56 \%$ of patients had some restriction to any type of food, while $6.3 \%$ were associated with religious motives, especially with respect to the group of meat. The other patients claimed restrictions for not liking the food $(34 \%)$ or have associated health problems $(16 \%)$. The expression of coercion not statistically significant $(P>0.05)$ between groups of patients with and without food restriction. Patients perceive that they are heard by the health team, but understand that their views are not considered when deciding on the types of foods that will be offered. Only $1.7 \%$ of patients said they would be embarrassed if asked about their religious practices.
\end{abstract}

Keywords: Bioethics; Nutrition; Coercion; Spirituality; Religious beliefs

\section{Introduction}

Bioethics reflects about much health related issues. Spiritual aspects involved in decision making are one of them. The inclusion of spiritual aspects in the Bioethics arena does not remove the secular character of bioethical reflection. In contrast, considering spiritual aspects may gave a broad and more complex understanding about motivations associated with the decisions that people make $[1,2,3,4]$.

The Clinical Bioethics Committee of the Hospital de Clínicas de Porto Alegre, since 1993, had the mission to assist health professionals, patients and families in bioethical issues associated with the decision making process [5].

In the vast majority of cases, involved families had some kind of vulnerability. Health proffessionals didn't recognize these situations easily [5]. Lack of knowledge or misconceptions about spiritual aspects related to health care, as well as the divergent opinions or beliefs, hindered the understanding and the resolution of conflicts. $(2,3,4)$

Individual food choices can be conditioned by a great variety of factos, cultural issues and religious beliefs are examples. In hospitals the religious influence in food is often omitted by the inpatients, mainly for fear of stigmatization by health professionals [6].

The healthcare team must be aware to recognize this diversity and avoid stereotypes, trying to clarify this prejudice related to spirituality issues, or other impediments, generated in the hospital, by the health team, patients and family [7]. Respect and knowledge of the spiritual dimension of the patient contributes to the relationship between healthcare team, patients and their family members, in health procedures.

The Complex Bioethics approach may help, serving as a framework in the search for the addequacy of actions justification. Complex Bioethics includes rational and non-rational issues when evaluate the addequacy of a stuation. Related cases and theoretical background, facts and circunstances, alternatives and consequences are considered as a whole. Affectivity, including bonds and desires, belief systems and values, expressed as traditions or as interests are considered too. Complex Bioethics reflection includes all of these issues, helping people to achieve a deeper understanding about the problem involved.

Under this assumption, it was considered that religious beliefs and values can influence the food options and the adherence to a nutritional treatment by inpatients and when they return to their homes.

This paper aims to investigate religious motivations related to food restrictions reported by inpatients in a unversity hospital.

\section{Methods}

A cross-sectional study was conducted involving inpatients at the Hospital de Clinicas de Porto Alegre (HCPA), a university hospital, located in Porto Alegre, Brazil. A sample of 271 adults inpatients from clinical and surgical units were interviewed about dietary restrictions.

Sample size was estimated using an expected food restriction rate of $5 \%$ at a significance level of $95 \%$ and $3 \%$ of absolute accuracy [8]. The semi-structured interview has a set of four questions about food restrictions and related motivations, and embarrassment about this issue. Socio-demographic data was also recorded. Religious denominations were grouped according to the Brazilian census classification [9].

Foods were classified into nine groups: Group 1 - Grains, Breads, Tubers, Roots; Group 2 - Vegetables; Group 3 - Fruits; Group 4 Legumes; Group 5 - Meat and Eggs; Group 6 - Milk; Group 7 - Sugar

*Corresponding author: José Roberto Goldim, Rua Ramiro Barcellos 2350 Porto Alegre 90035-903 Porto Alegre, Brazil, Tel: 555133598304; Fax: 555133598001; E-mail:jgoldim@hcpa.ufrgs.br

Received September 28, 2010; Accepted December 15, 2010; Published December 17, 2010

Citation: Wettstein MF, Ferreira Alves LN, Goldim JR (2011) Bioethics and Food Restrictions by Religious Motivations: Decision Making Processes in Health. $J$ Clinic Res Bioeth 2:106. doi: 10.4172/2155-9627.1000106

Copyright: (c) 2011 Wettstein MF, et al. This is an open-access article distributed under the terms of the Creative Commons Attribution License, which permits unrestricted use, distribution, and reproduction in any medium, provided the original author and source are credited. 
and Sweets; Group 8 - Oils and Fats; Group 9 - others, like alcoholic beverages, salt, etc. [10].

After the interviews a self-report instrument to assess the expression of coercion associated to food restriction. A Brazillian Portuguese version from the scale of Expression of Coercion, proposed by Gardner was used $[11,12,13]$. This scale comprises four questions, based on yes-or-not answers. Expression of Coercion values could range from zero to four, zero as the absence of expressed coercion and four as the maximum values.

Dietary restrictions by religious motivations reported by inpatients were compared with those reported by religious leaders from the same denomination to evaluate coherence.

Data analysis was performed using the SPSS system, version 18 . The $5 \%$ significance level was considered.

This project was approved by the HCPA Research Ethics Committee (GPPG 07364) and all research participants signed an Informed Consent Form.

\section{Results}

In a sample of 271 inpatients evaluated, $66 \%$ were female and $34 \%$ male, median age 51 years, range $16-85$ years.

The educational level, declared by the patients, ranged from illiterate to university degree. Most participants (61\%) had education corresponding to elementary education, consistent with the vast majority of patients treated at the Hospital.

As for the religious denomination, 232 (86\%) patients reported having had some practice linked to a specific group. Were cited 25 different religious denominations, which were classified according to Brazilian census criteria the most frequently reported categories were the Roman Catholic Church (55\%) and Evangelical Churches (15\%).

Of the 271 patients evaluated, $118(44 \%)$ reported not having any food restriction. The remaining 153 (56\%) subjects reported 286 different food restrictions, which were grouped into nine food groups (Philipp, ST et al, 1996 [10].

Three different categories of food restrictions motivations could be identified in the 153 patients reports: not liking the food (60\%), associated to health problems (29\%) and religious motivation (11\%). (Tables 1 and Table 2).

Not liking as a food restrictions were reported by 92 patients. This category was associated to 176 foods. Two different groups of food was mainly reported Group 2 - vegetables (48.3\%) and Group 5 - of meat and eggs (25.3\%).

Food restrictions associated to health problems were associated to 74 food restrictions reported by 44 patients. Group 5 - especially red meat (25.3\%), and Group 2 - vegetables (20.0\%) was the most cited.

A group of 17 Patients reported 35 different types of foods restricted by religious motivations. Group 5 - meat and eggs was the most cited (76, 0\%). It's important to refer pork and foods with blood as the most cited in this group. The second was Group 9 - other foods (14, 0\%), like drinks with alcohol or caffeine. Group 2 - vegetables $(12,0 \%)$ only two food types was cited: tomatoes and chayote, and Group 6 - milk (6, 0\%) was also cited. Other group was not cited.

Of the 17 patients with restrictions for religious motivations, $15(88 \%)$ were female and two (12\%) males. Compared to the whole sample, this sex distribution has no significant association $(\mathrm{X} 2=2.03$, $\mathrm{df}=1, \mathrm{P}=0.15 \mathrm{NS}$ ).

Among the 215 patients reported no restrictions for religious reasons, 198 (92\%) patients declared religion denominations that do not really have this kind of behavior expected. In this group are Catholics, Baptists and Lutherans, all with $100 \%$ coherent answers. However, 17 $(8,0 \%)$ patients declared to be members of religious groups that have some type of restriction, but not reported any food restriction.

The expression of coercion scale presents the higher mean value (1.72) in inpatients with restrictions for not liking the food. In all subsamples, mode was zero. All comparisons between patients' subsamples resulted not significant $(\mathrm{P}<0.05)$ (Table 3$)$.

Analyzing the answers to each scale item it's possible to identify that patients understand that they had opportunity to express opinions and to inform about their dietary restrictions. But the majority of them also expressed, however, that these views are not considered by health professionals when taking decisions about what food will be offered at meals.

Only $1.7 \%$ patients reported some embarrassment if they were

\begin{tabular}{|l|l|l|l|}
\hline Group of Food & Any Restriction (N = 153) & Dislikes (N = 92) & Health Problem (N = 44) \\
\hline Vegetables & $35.9 \%$ & $48.2 \%$ & $20.0 \%$ \\
\hline Meat and eggs & $27.4 \%$ & $25.3 \%$ & $25.3 \%$ \\
\hline Oils and Fats & $8.0 \%$ & $5.1 \%$ & $14.7 \%$ \\
\hline Fruit & $6.6 \%$ & $5.6 \%$ & $5.6 \%$ \\
\hline Cereals & $6.2 \%$ & $6.7 \%$ & $8.0 \%$ \\
\hline Sugar and sweets & $3.5 \%$ & $0.6 \%$ & $5.6 \%$ \\
\hline Pulses & $3.1 \%$ & $3.4 \%$ & $3.4 \%$ \\
\hline Milk & $3.1 \%$ & $3.4 \%$ & $3.4 \%$ \\
\hline Other & $6.2 \%$ & $1.7 \%$ & $0.0 \%$ \\
\hline Total & $100.0 \%$ & $100.0 \%$ & $14.0 \%$ \\
\hline
\end{tabular}

Table 1: Food groups and reasons for food shortages reported by 153 patients participating in the total sample of 271 study participants

\begin{tabular}{|c|c|c|c|}
\hline Religious Denomination $\left({ }^{*}\right)$ & Patients without Restrictions Food Religious n (fr) & Patients with Restrictions Food Religious n (fr) & Total Sample $n$ (fr) \\
\hline Roman Catholic & $149(58.7 \%)$ & $0(0.0 \%)$ & $149(54.9 \%)$ \\
\hline Evangelical Pentecostal Origin & $36(14.2 \%)$ & $5(30.8 \%)$ & $41(15.1 \%)$ \\
\hline Spiritualist & $13(5.1 \%)$ & $3(23.2)$ & $16(6.0 \%)$ \\
\hline Evangelical Mission & $9(3.5 \%)$ & $6(30.8 \%)$ & $15(5.5 \%)$ \\
\hline Umbanda & $6(2.4 \%)$ & $2(7.6 \%)$ & $8(3.0 \%)$ \\
\hline Jehova's Witness & $2(0.8 \%)$ & $0(0.0 \%)$ & $2(0.8 \%)$ \\
\hline Orthodox Catholic & $0(0.0 \%)$ & $1(7.6 \%)$ & $1(0.4 \%)$ \\
\hline No religion & $39(15.3 \%)$ & $0(0.0 \%)$ & $39(14.3 \%)$ \\
\hline Total & $254(100.0 \%)$ & $17(100.0 \%)$ & $271(100.0 \%)$ \\
\hline
\end{tabular}

$\left({ }^{*}\right)$ According to the classification of religious denominations in accordance with the criteria of IBGE/2000

Table 2: Religious denomination reported by participants with and without dietary restrictions for religious reasons $(n=152)$ 
Citation: Wettstein MF, Ferreira Alves LN, Goldim JR (2011) Bioethics and Food Restrictions by Religious Motivations: Decision Making Processes in Health. J Clinic Res Bioeth 2:106. doi: 10.4172/2155-9627.1000106

Page 3 of 3

\begin{tabular}{|c|c|c|c|c|c|c|c|}
\hline Sample & n & fr & Mean & Standard Deviation & Median & Mode & Minimum and Maximum \\
\hline food restriction in general & 152 & $56.5 \%$ & 1.61 & 1.61 & 1 & 0 & $0-4$ \\
\hline food restriction for not liking & 92 & $33.9 \%$ & 1.72 & 1.62 & 1.5 & 0 & $0-4$ \\
\hline food restriction due to health problems & 44 & $16.2 \%$ & 1.64 & 1.68 & 1 & 0 & $0-4$ \\
\hline food restriction by religious motivation & 17 & $6.3 \%$ & 1.65 & 1.53 & 2 & 0 & $0-4$ \\
\hline without food restriction & 118 & $43.5 \%$ & 1.51 & 1.60 & 1 & 0 & $0-4$ \\
\hline Total & 271 & $100.0 \%$ & 1.61 & 1.61 & 1 & 0 & $0-4$ \\
\hline
\end{tabular}

Table 3: Values with the Expression Scale of Coercion in a sample of 271 inpatients in relation to food restrictions.

asked by the healthcare team about their dietary restrictions. These patients had food restrictions for not liking or associated to health problems.

\section{Discussion}

It is important to remenber that were idenfied three categories of food restriction motivations: not like, associated to health problems and by religious motivation. Not like was the most frequent justification to food restriction. Group 2 - vegetables, was the most cited in this subsample. Group 5 - meat and eggs, was predominant in restrictions by religious motivations or associated to health problems.

Answers associated to religious motivations were coherent to the restrictions informed by religious leaders in $47 \%$ of cases, the remaining 53\% restrictions cited had no support in the doctrine of the denomination mentioned.

Another important finding, which indicates the lack of knowledge in this subject, was evidenced in the category of food restrictions associated to health problems. About $94 \%$ of the patients' alleged restrictions have no coherent relation to their health problem reported in patient records.

The Expression of Coercion in relation to dietary restrictions, obtained in this sample of 271 patients had an average of $1.61+1.61$. These values were significantly higher than those observed in another sample of 410 outpatients from the same hospital, which averaged $0.43+0.74(\mathrm{t}=11.85 \mathrm{df}=560, \mathrm{p}<0.05)$. But there were no significant differences between groups of patients with and without dietary restrictions, or between sub-groups for the stated reason. This shows a different pattern of expression of coercion, which can be attributed, perhaps, to the situation of being hospitalized.

As for the embarrassment of being asked about their religious aspects, the vast majority has no restrictions to this approach. This result is similar to that obtained in other studies $[13,14]$.

\section{Final Considerations}

- Based on these results, it's possible to conclude that

- food restrictions was reported by a great number of inpatients; food restrictions by religious motivations was reported by a restricted number of inpatients;

- meat was the most cited food restrictions by religious motivations;

- expression of coercion reported by inpatients didn't presents statistically significant differences between groups with and without dietary restrictions, and between different motives reported, but is significantly higher than that seen in outpatient clinics;

- inpatients realize they can express their opinion about food restrictions, but recognize that it is not taken into account by health professionals in the dietary decision making process;

- the vast majority of inpatients related no embarrassment about questions about religious practices.

These findings highlight the importance of shared decision-making with patients, to include other aspects in this process and enhance the role of personal opinions, beliefs and traditions. The dialogue between patients, families and health professionals builds trust and mutual understanding, and can increase adherence to treatment.

Hospitals could evaluate the operational and financial impact on offering dietary options to inpatients.

\section{References}

1. Goldim JR (2009) Bioetica Complexa: uma abordagem abrangente para o processo de tomada de decisão. Revista AMRIGS 53: 58-63.

2. Salgueiro JB, Wettstein MF, Raymundo MM, Nunes LVB, Bastiani F, et al. (2008) Dietary restrictions for religious motivation: implications in the decision making process facing health treatment. Rev HCPA 28: 252.

3. Goldim JR, Salgueiro JB, Raymundo MM, Matte U, Boer APK. (2007) Bioethics and Spirituality. $1^{\text {st }}$ ed. Porto Alegre: EDIPUCRS

4. Goldim JR, Bioethics and Spirituality [Cited in Aug 2, 2007]

5. Goldim JR, Raymundo MM, Fernandes MS, Lopes MHI, Kipper DJ, et al (2008) Clinical Bioethics Committees: A Brazilian Experience. J Int Bioethique 19: 181-192.

6. Slady A (1995) Bioethical concepts of health in medicine. Sb Lek 96: 195-198.

7. Daar AS, al Khitamy AB (2001) Bioethics for clinicians 21. Islamic bioethics CMAJ 164: 60-63.

8. Lwanga SK, Lemeshow S (1991) Determination of sample sizes in health studies. Geneva OMS: 1, 25

9. Brasil. Censo demográfico. Rio de Janeiro: IBGE 2000: 173-174.

10. Philipp ST (1999) Adapted Food Pyramid: Food Guide for food. Rev.Nutr Campinas, 12: 65-80

11. Gardner W, Hoge SK, Bennet N, Roth LH, Lidz CW, et al. (1993) Two scales for measuring patients perceptions for coercion during mental hospital admission. Behavior Science Law.

12. Taborda JGV (2002) Perception of coercion in psychiatric patients hospitalized medical and surgical. Porto Alegre: Federal University of Rio Grande do Su [PhD thesis].

13. Protas J (2010) Adaptation of the Scale of Perceived coercion in Research and range of Expression of coercion in Health Assistance Procedures for Porto Alegre: PPG in Medicine: Health Sciences / UFRGS. 